\title{
Conflict of interest: The case of a non-decision-making committee at a South African public higher education institution
}

\begin{tabular}{|c|c|}
\hline \multicolumn{2}{|c|}{$\begin{array}{l}\text { Authors: } \\
\text { Jacobus S. Wessels } \\
\text { Elmarie Sadler }{ }^{2} \text { (1) }\end{array}$} \\
\hline \multicolumn{2}{|c|}{$\begin{array}{l}\text { Affiliations: } \\
{ }^{1} \text { Department of Public } \\
\text { Administration and } \\
\text { Management, College of } \\
\text { Economic and Management } \\
\text { Sciences, University of South } \\
\text { Africa, Pretoria, South Africa }\end{array}$} \\
\hline \multicolumn{2}{|c|}{$\begin{array}{l}{ }^{2} \text { Department of Financial } \\
\text { Governance, College of } \\
\text { Accounting Sciences, } \\
\text { University of South Africa, } \\
\text { Pretoria, South Africa }\end{array}$} \\
\hline \multicolumn{2}{|c|}{$\begin{array}{l}\text { Corresponding author: } \\
\text { Jacobus Wessels, } \\
\text { wessejs@unisa.ac.za }\end{array}$} \\
\hline \multicolumn{2}{|c|}{$\begin{array}{l}\text { Dates: } \\
\text { Received: } 14 \text { May } 2020 \\
\text { Accepted: } 10 \text { Mar. } 2021 \\
\text { Published: } 28 \text { June } 2021\end{array}$} \\
\hline \multicolumn{2}{|c|}{$\begin{array}{l}\text { How to cite this article: } \\
\text { Wessels JS, Sadler E. Conflict } \\
\text { of interest: The case of a } \\
\text { non-decision-making } \\
\text { committee at a South African } \\
\text { public higher education } \\
\text { institution. J transdiscipl res } \\
\text { S Afr. 2021;17(1), a878. } \\
\text { https://doi.org/10.4102/ } \\
\text { td.v17i1.878 }\end{array}$} \\
\hline \multicolumn{2}{|c|}{$\begin{array}{l}\text { Copyright: } \\
\text { @ 2021. The Authors. } \\
\text { Licensee: AOSIS. This wo } \\
\text { is licensed under the } \\
\text { Creative Commons } \\
\text { Attribution License. }\end{array}$} \\
\hline \multicolumn{2}{|l|}{ Read online: } \\
\hline 回触回 & $\begin{array}{l}\text { Scan this QR } \\
\text { code with your } \\
\text { smart phone or } \\
\text { mobile device } \\
\text { to read online. }\end{array}$ \\
\hline
\end{tabular}

The avoidance of a conflict of interest within private and public institutions is closely associated with good corporate governance. This study departed from the question of whether a conflict of interest is possible within a non-decision-making institutional committee. For this purpose, a high-level non-decision-making committee within a South African public higher education institution was selected as a case study. This article reports on an exploratory qualitative study consisting of qualitative content analysis of the constituting and operational documents of this committee, as well as on a study of the perceptions and lived experiences of the selected committee. It was found that the selected committee was established to be a high-level consultative body for the executive management committee of the university on decisions of strategic operational nature. This committee does not have any decision-making duties. Conflict of interest is perceived by committee members in terms of either the explicit or the hidden agenda metaphor. According to the explicit agenda metaphor, a conflict of interest within a non-decision-making committee is not possible, whilst the hidden agenda metaphor holds that a conflict of interest is the reality of members' lived experiences. This article provides a comparison of the two perspectives according to three defining attributes of the concept and shows a need for a logical and principled definition of the concept 'conflict of interest' within the context of higher education and the public sector at large.

Keywords: conflict of interest; higher education management; corporate decision-making; consultative forum; internal competition; hidden agenda; explicit agenda; governance; higher education institutions; public higher education institutions.

\section{Introduction}

It is commonly accepted within soundly governed corporations as well as public sector institutions that the only value driver for members of boards and committees is to execute their duties, as articulated by the King IV report, 'in the best interest of the organisation over time'. ${ }^{1}$ Consequently, it is expected that members of these bodies will always 'avoid using their position and title to perpetuate sole self-interest or mere private gain'. ${ }^{2}$ The expectation of avoidance of conflicting interests in corporate decision-making is embedded in a rich literature on business ethics, corporate governance and public sector integrity. ${ }^{3,4}$ Conflict of interest, irrespective of the context, has shown to refer to an individual's private or personal interests, which may have an improper influence on the performance of his or her 'official duties and responsibilities'. ${ }^{5}$ These duties or responsibilities have shown to be predominantly that of judgement and decision-making. ${ }^{6,7,8}$

A crucial question, however, is whether conflict of interest is possible within a committee with no decision-making powers and, if so, what the nature of that conflict may be. This question is especially relevant considering that a self-assessment study amongst the members of a nondecision-making university committee has shown that the confidence level of committee members to 'properly manage potential conflict of interest' within the committee is at an 'extremely low level' ${ }^{9}$ This particular committee is mainly a consultative forum for the executive management of the university. The vexing question is thus as follows: how is it possible for conflict of interest to exist within such a committee? The subsequent purpose of this article is to report on a study of the possibility of conflict of interest experienced by members of a non-decision-making committee of a selected public higher education institution (HEI).

The HEI, with which the two researchers are affiliated, has been selected as a typical case of the phenomenon. An exploratory qualitative study amongst members of a non-decision-making 
committee in this institution was conducted to describe and understand their perceptions of the concept 'conflict of interest' within the context of this committee. The article reports on their lived experiences of potential conflict of interest within the committee, as well as their understanding of what proper management of this phenomenon entails. A brief background to the research and a justification of the theoretical perspective on the research problem and the research purpose are firstly provided. Secondly, the methodological and research ethics considerations for the research, specifically with the contentious topic in mind, are also discussed. Thirdly, an integrated and interpretive account of the research findings is discussed. The conclusions are then embedded in the relevant theoretical frameworks selected for this research as well as those that evolved through the research process for an improved understanding of the phenomenon.

The background of this study, embedded in the South African higher education context, as well as the theoretical frameworks underpinning corporate governance, is provided in the next section.

\section{Background}

This research project originated against the backdrop of the realisation of the imperative of good corporate governance within South Africa as a country, but also within the sphere of public higher education. The imperative of sound governance structures within HEIs is confirmed by:

- the Higher Education Act, 101 of $1997^{10}$

- the Regulations for Reporting by Higher Education Institutions ${ }^{11}$

- the Standard Institutional Statute ${ }^{12}$

- an institution-specific statute for each university ${ }^{13,14}$

- the legislature's consideration of the annual vote to fund the South African education sector. ${ }^{15}$

These regulations have shown to be closely aligned with the principles embedded in the King IV report on corporate governance. ${ }^{1}$ With regard to the promotion of ethical conduct, the report advises that members of governing bodies 'should avoid conflicts of interest' ${ }^{1}{ }^{1}$ Considering that public HEIs are also classified as part of the broad public sector, it is noteworthy that the Organisation for Economic Co-operation and Development (OECD) also advises against a conflict of interest resulting in an improper influence on the performance of their [public officials] official duties and responsibilities'. ${ }^{5}$

The South African public HEI, which served as a case for this study, has shown to be fully aligned with the abovementioned regulatory framework and with the imperative of sound corporate governance. ${ }^{16}$ As part of the university's continuous efforts to improve governance structures and practices, the Bureau of Market Research (BMR) was commissioned by the executive management of the university to conduct 'self-assessment' studies to gauge the efficiency of the functioning of the various structures and committees within the university. One of these committees is the Extended Management Committee (EMC) - a highlevel consultative committee for the executive management of the university.

The self-assessment study performed on this committee investigated, inter alia, the confidence and perceptions of individual committee members regarding 23 survey items. ${ }^{9}$ The report states, 'confidence in the EMC and its members is at an extremely low level ... and has remained low and even deteriorated since 2014'. ${ }^{9}$ One of the low-confidence items was identified as '[committee members] properly manages [sic] potential conflict of interest'.

The BMR study revealed that the confidence level index for managing committee members' conflict of interest was below 50\% for three consecutive years (2013-2015): 48.81\% in $2013,45.59 \%$ in 2014 and $47.37 \%$ in 2015 . An analysis of the raw data also showed a strong correlation between this item and three other items, namely, 'transparent in exchanging information openly' (correlation: 0.748), 'mutual respect for responsibilities and views of other members' (correlation: 0.707) and 'receive feedback on how issues are resolved' (correlation: 0.677). It thus seems that the concepts 'transparency', 'mutual respect' and 'feedback' may be key concepts within a broader theoretical context of understanding the phenomenon 'conflict of interest' and its management within this committee.

\section{Theoretical and operational contexts}

The current study was performed within the theoretical context of corporate governance and the operational context of higher education management. It set out to obtain a deepened understanding of the overlapping theoretical concepts 'corporate governance' ${ }^{\prime 17}$ and 'conflict of interest' ${ }^{\prime 18}$ within the context of HEIs. ${ }^{6,19}$ For the purpose of this study, the theoretical and operational contexts were directly interrelated and fully integrated.

The operational context of this study consisted of the broad higher education environment as well as a specific institutional context of a selected university. The transformation of South African universities has shown to be closely aligned with a worldwide trend of universities transformed from:

[S]mall, elite institutions, managed by academic peers in a collegial way, into large multi-task organisations. This requires new governance structures to manage all the tasks and roles of today's institutions..$^{20}$

This transformation of especially South African universities has been justified as an attempt to strengthen governance through 'an integrated, unified higher education system based on the principles of equity, democratisation, quality, academic freedom, institutional autonomy, effectiveness and efficiency' ${ }^{21}$ 
The efforts to strengthen governance in South African universities are informed by, inter alia, the work and influence of the various King reports on corporate governance in South Africa. The King IV definition of corporate governance is widely used as a foundational guideline, namely 'the exercise of ethical and effective leadership by the governing body towards the achievement of the ... governance outcomes' of ethical culture, good performance, effective control and legitimacy. ${ }^{1}$ This definition was used as a primary assumption for this article. Furthermore, the legal foundation for governance of South African public HEIs is provided in Chapter 4 of the Higher Education Act, 101 of $1997 .{ }^{10}$ This foundation, specifically with regard to the governance structures and offices in HEIs, is supplemented by the Standard Institutional Statute ${ }^{12}$ and, for each university, an institution-specific statute. ${ }^{13,14}$

In terms of the King IV definition of corporate governance, a university council is the governing body of a university and thus primarily responsible for efficient governance within the university. ${ }^{10,12}$ The Higher Education Act of 1997 provides for institutional governance structures, such as a council, a senate, a principal, a vice-principal, a students' representative council (SRC), an institutional forum and 'such other structures and offices as may be determined by the institutional statute'. ${ }^{10}$ With these governance structures in mind, the Standard Institutional Statute refers to council committees, joint committees of the council and the senate, senate committees, subcommittees of the senate, an executive committee of the senate, student committees and SRC committees. ${ }^{10,12}$ The statute of the selected institution provides, in addition to the aforementioned structures, also for college boards, an inter-college board, a management committee and an EMC. ${ }^{13,14}$ Whilst the aforementioned structures and committees are all constituted in terms of the Higher Education Act of 1997 and related statutes and regulations, these committees all seem to be included in the corporate governance responsibility of a university council.

The higher education system in South Africa is thus characterised by its dense corporate governance systems through which university councils and senates have the obligation to ensure an 'ethical culture, good performance, effective control and legitimacy'. ${ }^{1}$ The EMC, which constituted the narrow context of this study, is thus included in the above-mentioned system, which comprises the governance responsibility of the university council. It was within these overlapping contexts of corporate governance and higher education that this study searched for an in-depth understanding of the concept 'conflict of interest'.

The King IV report advises that conflict of interest of members of a governing body should be avoided in the pursuit of integrity and ethical leadership. ${ }^{1}$ To this end, the concept 'conflict of interest' is used to describe a situation of 'direct or indirect conflict, in fact or in appearance, between the interests of such member and that of the organisation'. ${ }^{1}$ The primary assumption of this definition is that the interest of the organisation is paramount. The implication is thus that any relationship of a member of such a body or committee 'that is or appears to be not in the best interest of the organization' constitutes conflict with the interest of the organisation, which would subsequently 'prejudice an individual's ability to perform his or her duties and responsibilities objectively'. ${ }^{22}$ The literature reveals that these duties predominantly relate to members' roles in the decision-making process of such a board or committee. ${ }^{18,23}$ Whilst the emphasis on improved corporate governance might have originated in the business sector, there is a worldwide trend towards improved governance requirements for what is known as non-profit organisations, with specific emphasis on conflict of interest. ${ }^{4}$ In a legal study on the limits of conflict regulations within the context of private life, Guzzetta ${ }^{24}$ identified three basic elements that constitute a situation of conflict of interest, namely:

- a legally qualified position (social, economic, institutional),

- two different interests in actual or potential contrast and

- what I call a 'power-duty' (stemming from a private or public office) to discharge.

Reporting on a study on conflict of interest in Canadian universities, Williams-Jones and MacDonald ${ }^{8}$ report that the primary concern in the university context is that conflict of interest:

$[T]$ hreatens the objectivity, impartiality and credibility of judgments, whether in academic research or professional decision-making, and leads to a subsequent loss of trust by staff, students and the broader public.

Within the context of the South African higher education sector, research revealed 'a renewed focus on the declaration of conflicts of interest', resulting in a number of universities adopting policies and procedures to mitigate the risk of conflicts of interest. ${ }^{25}$ Within the context of this specific case, the 'Code of Ethics' of the university under study refers to a possible conflict of employees' 'private interests and their obligations to [the university]', ${ }^{26}$ whilst the 'Terms of Reference' of this specific committee do not contain any reference to the possibility of a conflict of interest. ${ }^{27}$

Where 'conflict of interest' is used in the literature, it is done with reference to the possible impairment of the duties of committee or board members to make a decision on an item on the agenda of a meeting. The following assumptions applicable to corporate governance and the avoidance of conflict of interest in a public university can be extracted from the preceding discussion:

Assumption 1: The university council is the governing body of a university and has the entitlement, power and obligation ${ }^{24}$ to make decisions regarding efficient governance of that university through its duly constituted office bearers and structures.

Assumption 2: Efficient corporate governance by the council and its subordinate office-bearers and structures implies the entitlement, power and obligation to exercise ethical and effective leadership towards the achievement of the governance outcomes of the university. 
Assumption 3: Ethical and effective leadership by office-bearers and members of council or its subordinate structures implies that entitlements, powers and obligations in conflict with the interests of the institution should be avoided.

The above assumptions were used as theoretical points of departure for this study.

\section{Research problem and research purpose}

A common attribute to the preceding three theoretical assumptions deduced from the literature is the presence of an active actor who is making decisions or who exercises leadership. The ethical dilemma of a conflict of interest experienced by an active actor is thus a direct result of the actor's decision to act in a specific way in response to an agenda item. This dilemma leads to the vexing question, which drove this study, namely, 'How is it possible that a conflict of interest can be experienced within a committee that does not make any decision on any agenda item?' The subsequent purpose of this article is to report on a study that set out to understand the possibility of conflict of interest within a nondecision-making committee in a selected HEI. The aforementioned non-decision-making committee was thus the unit of analysis of this study, whilst the possible existence of a conflict of interest within the committee served as the specific point of focus. Consequently, this study set out to understand the possibility of a conflict of interest within this committee through its key constituting documents as well as the perceptions and experiences of the members of the committee. The research design and methodology necessary to conduct this study are summarised next.

\section{Methodology}

As a preliminary review of the literature revealed the absence of an existing theoretical body of knowledge regarding the existence of conflict of interest within non-decision-making committees, the researchers decided to embark on an exploratory qualitative research design to obtain a comprehensive understanding of this phenomenon. ${ }^{28}$ Two methods were applied, namely, content analysis of selected documents and face-to-face individual interviews with members of the committee. This project thus relied on two categories of sources: documents and individuals who were members of the committee.

Although members of the committee served as the primary unit of observation for this study, the researchers firstly performed a qualitative content analysis of several key documents, which included the 2015 self-assessment report, ${ }^{9}$ the 'Terms of Reference' of the committee, ${ }^{27}$ the university's 'Code of Ethics' ${ }^{\prime 2}$ and a selection of recent agendas and minutes of the committee. The aims of the summative qualitative content analysis ${ }^{29}$ were to gain a complete understanding of the context of the individual participants by comprehending the composition, purpose and functions of the committee, the various interests at stake, as well as the meaning of the concept 'conflict of interest', within both the broader HEI context and the context of this committee.

Secondly, face-to-face interviews were conducted with members of the committee. An interpretive phenomenological approach was used to generate rich and detailed descriptions ${ }^{30}$ of how the members of the committee perceived and experienced the possibility of a conflict of interest within the committee. With the selection of this approach, the researchers assumed that the perceptions and experiences of the participating committee members were real and worthy and that exploring such perceptions and experiences and taking them into account were pivotal for obtaining an indepth understanding of the phenomenon. ${ }^{31,32}$ The interviews were directed by the following three broad and open-ended questions with no right or wrong answers ${ }^{33}$ :

- How do you perceive the concept 'potential conflict of interest' within the context of the EMC?

- Reflecting on your role as a member of the EMC, can you share your experiences of what you regard as potential conflict of interest within the EMC?

- Reflecting on your experiences, what does it mean to you to 'properly manage' potential conflict of interest within the context of the committee?

The empirical nature and the possible sensitive topic of this study had specific ethical implications, which are discussed in the next section. The results of the first part of this research project, namely, the document analysis, are discussed in the next section.

\section{Ethical considerations}

Because of the potential sensitive nature of the project as well as the direct involvement of human participants, the researchers regarded the potential risk of harming human participants ${ }^{39}$ as moderate to high. They therefore applied for research ethics clearance at the Research Ethics Review Committee of the Faculty of Education, as this committee and its members were not directly related to the researchers' immediate sphere of influence. Research ethics clearance was granted on 11 February 2016 (reference number: 2016/02/11/1959611/49/MC). Subsequently, the researchers applied at the selected institution's Research Permission SubCommittee for permission to involve staff members in the research project and to gain access to official documents related to this project. Permission was granted on 03 March 2016 (reference number: 2016_RPSC_011).

In order to avoid a possible conflict of interest, with one of the researchers being a member of the committee, the researchers decided that the non-member researcher would conduct, record and transcribe the interviews with the selected members of the committee, whilst both researchers would analyse the anonymised interview records (numbered P01 to P10) and interpret the findings. All the members of the committee were invited by way of an e-mail to be available 
for a non-structured individual interview and to indicate their availability in a return e-mail. As only two members responded, additional members were consequently invited to make themselves available for an interview. Appointments were secured with 10 members of the committee, representing members from the executive management of the university, the academic sector as well as the support sector within the university. All members willing to participate received an informed consent letter and subsequently signed an informed consent form before the interviews commenced.

\section{Document analysis for understanding the committee as context}

To understand the perceptions and lived experiences of the members of the committee in terms of conflict of interest, it was necessary to understand the committee as context - the reason for existence of the committee, its composition and actual activities. For this purpose, an analysis was done of the documents providing that information, namely:

- Terms of Reference: EMC (as revised and approved by the Management Committee on 12 October 2015)

- a selection of recent agendas and minutes of the committee

- the particular university's 'Code of Ethics' ${ }^{26}$

\section{Reason for existence of the committee}

The reason for existence of the committee is stipulated as 'Functions of Committee' in section 4 of the 'Terms of Reference' ${ }^{27}$ Three themes could be identified from the analysis of this document to understand the reason for the existence of the committee, namely, the characteristics of the committee, the scope of its focus and the nature of its actions. The characteristics focus and actions of this committee relate directly to the interest of the committee as an institution. This is evident from key concepts, such as 'represented by Senior Management', 'Management Committee', 'the University', 'integrated and coordinated' and 'combined assurance ${ }^{\prime 27}$ As indicated earlier in this article, this committee forms part of the governance structure of the university council. ${ }^{10,12,34}$ This reason for the existence of the committee primarily involves supporting the council's governance structure within the university. The supporting role comprises being a consultative body assisting the Management Committee of the university to make informed (coordinating, integrating, monitoring, evaluating, performing and ensuring) decisions of a strategic operational nature in the interest of the institution as a unit. Hence, it was clear that this committee, although not a decision-making committee, is a formal part of the governance structure of the university. It is within these overlapping contexts of corporate governance and higher education that the current study searched for a thorough understanding of the concept 'conflict of interest'.

\section{Composition of the committee}

The composition of this non-decision-making committee reflects its important nature. This is described in section 1 of the committee's 'Terms of Reference'. ${ }^{27}$ All staff members appointed in management positions - from the level of deputy executive dean and deputy executive director to the principal and vice-chancellor (section 1) - are members of this committee. This implies that the committee can be regarded as representative of the university as an institution, as it consists of executive management (nine members), as well as the executive deans and deputy executive deans of the eight faculties (16 members), and the executive directors and deputy executive directors (18 members) of the support departments. These three groups constitute the distinct interest groups within the broader context of the university.

\section{Actual activities of the committee}

The committee was constituted to serve as a consultative body, consisting of senior managers representing all spheres within the university, assisting the executive management of the institution to make informed (coordinating, integrating, monitoring, evaluating, performing and ensuring) decisions of a strategic operational nature in the interest of the institution as a unit. The nature of the institutional interests (themes and topics of the agenda items) on which the non-decision-making committee has been consulted was identified, as well as the specific constituting sector (interest group) responsible for the themes or topics included in the agendas of the committee meetings for one academic year.

Content analysis of the minutes of the non-decision-making committee meetings was done to describe and understand the agenda items and the distinct role-player category (executive management together with the academic and support sectors) that presented these items and the activities of the committee. This analysis also revealed that no member of the committee declared a conflict of interest in the applicable column on the attendance registers for the respective meetings.

The analysis furthermore revealed that, of the 32 agenda items (excluding the approval of minutes) considered at the selected meetings of the committee, 17 items were of a purely operational nature focusing on portfolio or support department-specific operational matters. The focus of discussions by the committee was predominantly determined by the support sector of the university, as no fewer than 24 of the 32 agenda items were presented by a member from the support sector. Members of the executive management were responsible for four agenda items, whilst the executive management together with the academic and support sectors were shown to be jointly responsible for four agenda items. Not one agenda item was presented by the academic sector alone, a confirmation that this committee forms part of the governance structure of the university council, and not of the senate.

It was evident from the analysis that the agendas of the committee meetings were predominantly structured around 
taking notice of operational issues and presentations related to the various support departments, and that no member of the committee ever declared a conflict of interest.

\section{Considering that:}

- this committee is supposed to be a consultative body assisting the Management Committee of the university to make informed (coordinating, integrating, monitoring, evaluating, performing and ensuring) decisions of a strategic operational nature in the interest of the institution as a unit

- the committee meetings were predominantly structured around the notification of operational issues and presentations related to the various support departments

- no declaration of conflict of interest by a member of the committee was recorded in the minutes, this study set out to answer the following question: How can the relative lack of confidence amongst committee members to properly manage a possible conflict of their private interests with their obligations to the university be understood?

Key to finding an answer to this question was an understanding of the perceptions of the committee members of the concept 'conflict of interest' within the context of this committee, their lived experiences of the potential conflict of interest within the committee, as well as their understanding of what the proper management of this phenomenon entails. For this purpose, exploratory qualitative interviews were conducted with 10 members of the committee. The next section reports on the results of those interviews.

\section{Potential conflict of interest: Perceptions, lived experiences and expectations of committee members}

The purpose of these interviews was to grasp how the members of the non-decision-making committee understood the proper management of potential conflict of interest within the context of the committee. Consequently, the researchers sought to determine how members perceived the concept 'conflict of interest' within the context of this committee, how they experienced the phenomenon within this committee and how they expected this phenomenon to be managed.

This section reports on the analysis of the interview records of 10 members of the committee structured around three questions. The three main questions for the interviews as set earlier in this article serve as subheadings for this section.

In the process of studying the interview records, two distinct themes evolved, namely, that of the explicit agendas and that of the hidden agendas of the meeting. These themes were especially helpful in identifying two distinct understandings of the concept 'conflict of interest', namely:
- an explicit, legal concept referring to a prima facie possibility that judgement related to a decision to be taken might be impaired by other interests than those stated in the explicit agenda for the decision

- a non-legal concept referring to the exploitation of the explicit agenda to influence the judgement and subsequent decisions in other spheres of the institution to the advancement of individual or sectoral interest.

These themes have shown to become powerful metaphors in structuring and interpreting the results obtained from the interviews, as presented next.

\section{Question 1: How do you perceive the concept 'potential conflict of interest' within the context of this committee?}

This question was formulated by taking into consideration the interviewees' considered opinions on the meaning of a specific concept (potential conflict of interest) within a particular context, namely, this non-decision-making committee, the university and the broader higher education landscape. The analysis of the interview records revealed that the non-decision-making committee members' understanding of the concept 'conflict of interest' was closely related to the agenda of the committee meetings.

\section{Explicit agenda}

The interviewees who answered this question from the explicit agenda perspective argued that, at the time, it was expected from the committee members to declare on the attendance register any conflict of interest upfront (P04; P07). Should a member make such a declaration, that member should be asked 'when that item is discussed, to leave the room, and wait for the item to be discussed' (P07, face-to-face interviews, EMC). However, an analysis of the attendance registers of the committee meetings for an entire year confirmed that nobody had ever declared a conflict of interest when they signed the registers.

The question subsequently arose why no member of this committee had ever declared a conflict of interest. The reason provided was that the committee 'does not actually take decisions' as it 'is a talk shop' (P01). In terms of the legal meaning of the concept, conflict of interest can only occur if the members take decisions on which this committee is supposed to 'advise' and which they have to 'consider' (P01, face-to-face interviews, EMC). There seems to be an acknowledgement that 'we all go in with interests' (P03, face-to-face interviews, EMC) and that these interests may even be a 'strong personal interest in a matter under discussion' (P04, face-to-face interviews, EMC). This view has been illustrated as follows by one interviewee: 'I have a serious interest in the student system because, at the moment, the way the student system does not work, affects my life' (P03, face-to-face interviews, EMC).

The legal interpretation of the concept entails that 'the mere fact that you have competing interests does not mean that 
there is a conflict', as the 'only time where a conflict arises and is significant is when it impairs your judgement on a specific decision' (P01, face-to-face interviews, EMC). At the time, the agendas for meetings of this committee were structured in a fixed manner (P06) with items even perceived by some members as of a confidential nature (P08), which are included 'most of the time for noting' only (P06, face-to-face interviews, EMC). In terms of the legal understanding of the concept 'conflict of interest', at the time, the explicit agenda of this committee implied that a conflict of interest was not possible at its meetings. The fact that the attendance registers of the selected meetings did not reveal any declaration of conflict of interest probably proves that when members were signing that register, they applied the legal meaning of the concept.

\section{Hidden agenda}

As in the case of the explicit agenda discussed previously, the hidden agenda approach accepts that individual members enter meetings with interests (P01-P07; P09 and P10). However, it differs from the explicit agenda approach on whether that interest constitutes a conflict with the interest of the institution. The hidden agenda approach argues that whilst these personal or portfolio-specific interests may be driven in order to unduly influence decisions in other spaces, these interests indeed constitute a conflict with the common interest of the institution.

Irrespective of the application of the legal meaning of the concept when signing the applicable register, the $\mathrm{BMR}^{9}$ report reveals low confidence in managing conflict of interest amongst the members of this committee. This might be a confirmation of a tacit conflict of interest determined by another agenda: the hidden agenda. Conflict of interest in terms of the hidden agenda is perceived as the exploitation of a vague and undefined explicit agenda of the committee by strong personalities driving personal and portfolio-specific interests to influence decisions at other levels (P02; P03; P04; P09 and P10).

Conflict of interest within this committee is perceived by the participants as a reflection of the 'organisational model of the university [which] is very hierarchical, in fact, very industrial' (P02, face-to-face interviews, EMC), leading to an agenda that is 'almost competitive rather than collaborative' (P02, face-to-face interviews, EMC). The hierarchical model of the institution 'creates unnecessary conflict around power and who makes decisions' (P02, face-to-face interviews, EMC), probably as it does not manifest 'the academic project as being central' (P02, face-to-face interviews, EMC). These structural and personal hidden agendas 'may be demonstrated by members following a defence mode on a particular matter' (P04, face-to-face interviews, EMC), instead of having 'an open discussion' (P06, face-to-face interviews, EMC) on the 'common interest and your role to achieve it together with others' (P04, face-to-face interviews, EMC).
Irrespective of the fact that the attendance registers of the selected meetings did not reveal any declaration of conflict of interest, the analysis of the interview records from a hidden agenda perspective revealed the existence of various and powerful hidden but conflicting agendas, which might have influenced the behaviour of committee members to the possible detrimental interest of the institution.

Whilst the purpose of the first question was to obtain the committee members' perceptions or understanding of the concept within the context of this committee, the next question aimed to obtain their lived experiences of conflict of interest within the committee.

\section{Question 2: Reflecting on your role as a member of the committee, can you share your experiences of what you regard as potential conflict of interest within the committee?}

The second question was asked to obtain an understanding of the committee members' lived experiences of conflict of interest within the committee. Their experiences indicated that this was determined by their perceptions of the concept 'conflict of interest' within the context of the committee, as discussed in the previous section. Within the context of the committee, conflict of interest was experienced differently by members in terms of the two agenda metaphors.

\section{Explicit agenda}

Those members whose experiences were determined by their views of committee deliberations in terms of the explicit agenda of the committee and the concept 'conflict of interest' in its legal sense could not recall any instance that could be regarded as a conflict of interest. They substantiated their answers by referring to the absence of conflict between a member's private interest and the interest of the institution (P01; P04; P07). The experiences from a hidden agenda perspective were however different.

\section{Hidden agenda}

Conflict of interest was experienced by members of the committee as conflict between the interests of the particular (sector within the university) and the common (the university as a unity). The hidden agenda enhances conflicts of interests through its lack of focus on the strategic objectives of the university and attention to individual portfolios and their performances.

The culture of a silent majority (P09) and reluctance to share information (P06) were ascribed to '[f]ear for the pack of wolves' (P07, face-to-face interviews, EMC), or 'the punishment by the court' (P02, face-to-face interviews, EMC) and a fear of being exposed as making mistakes, as 'there is no room for making mistakes' (P06, face-to-face interviews, EMC). This seems to make it difficult for some members to express their views on particular matters. As one interviewee explained: 
'Sometimes the difficulty arises in that you know the committee so well, you know then when it is time to keep your mouth shut ... as it [expressing your opinion freely] could be actually careerlimiting.' (P06, face-to-face interviews, EMC)

The reality of a conflict of interest in the committee is therefore experienced notwithstanding the absence of decision-making powers of the committee. The influence of deliberations in the committee is, on the one hand, on the decisions taken by the Management Committee and, on the other hand, on the final decision-making structures (P05). Thus, although issues would be raised in the committee, 'the actual change, the approval for the change, would take place in another place' (P01, face-to-face interviews, EMC). Conflict of interest within the committee was accordingly described as 'determining the mood for decisions taken by other bodies' (P04, face-to-face interviews, EMC).

At the time of this study, conflict of interest in the committee was experienced in terms of the functionality of the committee, the composition of the hidden agendas for the meetings, the culture within the committee, and the extended influence of the activities of the committee. Within the committee, conflict of interest is perceived as directly related to the functionality of the committee. One of the major concerns regarding the functionality of the committee is that its explicit functions seem to be underutilised.

\section{Question 3: Reflecting on your experience, what does the expectation to 'properly manage' potential conflict of interest mean within the context of the committee?}

The purpose of the third question was to obtain the participants' views about the proper management of potential conflict of interests as informed by their lived experiences as members of the committee. This was done in an attempt to make sense of the concept ' $[t]$ o properly manage' potential conflict of interest within the committee by exploring the various possibilities to handle, control or cope with conflict of interest. Whilst the agenda metaphor was highly applicable in making sense of the perceptions of the interviewees, the perceptions and lived experiences of the participants revealed that the agenda itself might be a powerful vehicle to 'manage' conflict of interest in this committee. The latter argument was shown to be a common theme raised by nearly all the interviewees. Their views are presented in the following paragraphs as their reflections and understanding of both the explicit and the hidden agendas of the committee.

\section{Explicit agenda}

From the explicit agenda perspective, this question was perceived as irrelevant, whilst the self-assessment report and the subsequent investigations by the various working groups were perceived as an effort 'trying to massage this committee into something' (P01, face-to-face interviews, EMC). Entering a committee meeting with a specific sectoral interest was not perceived as having a 'conflict of interest' in the legal sense of the concept (P03). However, to 'properly manage' the diversity of especially sectoral interests in the committee was perceived as a rational activity by 'listening to other viewpoints and interrogating that' (P03, face-to-face interviews, EMC).

\section{Hidden agenda}

From the hidden agenda perspective, there was a firm acknowledgement of the presence of a structural conflict of interest within the committee (P02). Consequently, to properly manage a conflict of interest within the committee was perceived as to change the focus and functioning of the committee as well as the culture within the committee through a fundamental restructuring of the agenda. One interviewee formulated this proposed change as, 'I think integration is the name of the game' (P02, face-to-face interviews, EMC), referring to restructuring the explicit agenda to focus on the strategic matters and an all-inclusive scope for the committee. It was therefore suggested that each meeting should have a 'strong strategic focus' (P02, face-to-face interviews, EMC). Other interviewees emphasised the need for the agenda to focus on institutional goals and strategy (P05; P07). A change of scope and focus of the committee was regarded as pivotal for limiting the possibility for a conflict of interest within this committee. The focus of meetings should be on the achievement of institutional goals and strategy through an integrated involvement of all role-players in the institution (P02; P04; P06).

There seemed to be general agreement that the functioning of this committee needed to be changed to become a forum to deal with these strategic issues in an open and transparent way, and to deal with operational issues of a strategic nature (P06; P08-P09). The role of the chair of the committee, namely, to change the functioning of this committee, was perceived as vital for redirecting the functioning of the committee to strategic issues. The 'chair should take control and run this committee' (P10, face-to-face interviews, EMC). The analysis of the interview records also revealed a consequential relationship between the focus and functioning of the committee and its culture.

For the purpose of this study, we understood the concept 'culture' as referring to the 'assumptions, values and artefacts $^{\prime 35}$ within the committee. The most dominant culture experienced within the committee seemed to be the silo or sectoral culture, and a culture of fear for making mistakes and being blamed (P02; P06-P07; P10). There was also a strong view that conflict of interest within the committee would be limited if the culture was to be changed from a silo or sectoral interest to a shared institutional interest, and from a blame and shame culture to one of openly and honestly acknowledging mistakes, with a subsequent shared search for solutions to the benefit of the institutional interest.

From the hidden agenda perspective, there was thus a firm acknowledgement of the presence of a structural conflict of 
interest within the EMC (P02). There was also a clear expectation amongst the interviewees of this conflict of interest being properly managed through a change in the focus, functioning and culture of the committee by a fundamental restructuring of the explicit agenda.

\section{Discussion of results}

This study set out to make sense of the possibility that members of a non-decision-making committee within a public HEI may experience a conflict of interest. This issue is important, as the avoidance of conflict of interest is generally regarded as one of the foundational principles of good corporate governance.

Subsequently, this study departed from three theoretical assumptions, which linked the avoidance of a conflict of interest within an institution, such as a public university, to the soundness and efficiency of the corporate governance by the duly entitled, authorised and duty-bound university council and its office-bearers and structures. This study also showed that the committee that was selected as a case for this study formed an integral part of the governance structures established by the university council. This implied that the members of this committee also had to avoid entitlements, powers and obligations that were in conflict with the interests of the institution.

In an attempt to make sense of this specific case, this study commenced by obtaining a theoretical perspective on the avoidance of conflict of interest within the context of efficient and sound corporate governance. In the process of exploring the literature on the concept 'conflict of interest', it became evident that this concept is used within different contexts, with relatively similar defining attributes, antecedents and consequences. However, there seemed to be contextual differences in the criteria for identifying and describing those defining attributes of the concept and the real-life phenomenon to which it refers.

The theoretical analysis of the concept 'conflict of interest' in this study revealed the following defining attributes within the broader context of governance and the specific context of higher education governance: an individual with a legally established position, holding two different interests, with a power-duty to discharge. ${ }^{24}$ There seemed to exist general agreement about these defining attributes as the structure of the concept and the practical phenomenon. The difference in the understanding and meaning of the concept seemed to be caused by the interpretation of the second and third attributes, namely, the holding of two different interests and the nature of the so-called 'power-duty'. The bulk of the literature clarifies the attribute related to the two different interests as referring to private or outside interests versus institutional interests. $5,8,24,36$ Furthermore, the exercise of the power-duty, which may make the potential conflict of interest a reality, is described by most authors as a decision-making obligation. ${ }^{6,7,8,18,23}$ It is thus argued that conflict of interest within a committee or board occurs when a member of that body experiences an interest from outside the body, which may influence his or her power-duty to make a decision. This understanding of the concept 'conflict of interest' thus served as a theoretical point of departure for this study.

As indicated earlier, the committee that served as a case for this study evidently had no decision-making powers and thus no power-duty. The question was therefore how a conflict of interest was possible if one of the defining attributes was missing.

The first part of this empirical study set out to verify the assumption about the lack of decision-making powers of the committee under study by performing a qualitative content analysis of all documents relevant to this committee. This analysis confirmed that the membership of the committee was connected to the members' legitimate positions within the institution, but that they did not have any decisionmaking powers. The 'Terms of Reference' of the committee revealed that the committee was established by a consultative body assisting the Management Committee of the university to make informed decisions of a strategic operational nature in the interest of the university as an institution. The analysis of the relevant constituting and operational documents of the committee confirmed that this committee did not have any decision-making powers and thus did not have any powerduties either.

An analysis of the agendas of the committee revealed that meetings were structured around taking note of operational issues and presentations related to the various support departments. No evidence could be found from the minutes that any member ever declared any conflict of interest. Considering that an earlier survey amongst members of this committee indicated low confidence to manage a potential conflict of interest, ${ }^{9}$ the next step in the study was to engage with these members through face-to-face open-ended interview questions.

This study found that members of this committee approached the question of conflict of interest within this committee from two metaphorical perspectives, namely, from an explicit or a hidden agenda (see Table 1). The perspective of the explicit agenda was shown to be closely aligned with the widely accepted interpretation of the concept 'conflict of interest', namely, that it is only possible if the power-duty of the committee member is to participate in the decision-making process of the committee. Subsequently, the members had no lived experience of conflict of interest within the committee.

The view from the hidden agenda perspective highlighted two of the three attributes of the concept, namely, the location of the conflicting interest and how committee members may discharge their power-duty. The hidden agenda perspective revealed a different perspective on the location of conflicting interests. Whilst the explicit agenda perspective describes the conflicting interest as of a private or personal nature located outside the institution, the hidden agenda perspective 
identifies real conflicting interests, which may not be private, but sectoral and personal.

The EMC was a case of a committee with a sectoral composition. Whilst the committee consisted of specific administrative or academic office-bearers within the university at the time, the majority of the members represented specific sectoral interests (e.g. faculties or support departments) within the university. Even the members of the executive management of the university (e.g. the vice-principals and the registrar) serving in this committee represented portfolio or sector-specific interests in the committee. It was only the vice-chancellor and chairperson of the committee that could be seen as having the university as only interest. It was thus evident that it was possible for committee members to experience conflict between their institutional interests and their sectoral and personal interests within the institution. The location of their conflicting interests was thus not outside the institution, but inside. These institutional sectoral interests might thus not have been private, but were still personal. Interests were personal as the member had, through the integrated performance review system, a personal interest in the well-being of the particular sector he or she represented. This was a crucial new perspective on the second defining attribute of the concept 'conflict of interest'.

What are the possible reasons for these conflicting interests within the committee? The current research provided support for the argument that the lack of a strategic focus in the explicit agendas for the committee meetings fosters the hidden agendas of sectoral interests within the institution. This entails the emphasis on the day-to-day operational challenges of the competing, vertical sectoral structures of the institution and the committee's neglect of issues of a critical and strategic nature pertaining to the university as an institution. The conflicting sectoral interests within the committee have been found to serve as a proxy for personal interests. DeAngelis ${ }^{36}$ refers to this instance of interest as an indirect benefit to the individual. At the time, the culture within the committee, which was perceived to enhance conflict of interest to the detriment of the institution, was characterised by, inter alia, the uneven distribution of power, for example, the power and influence related to the institutional knowledge of a particular individual as opposed to the lack of institutional knowledge of other individuals. Furthermore, the culture was characterised by fear of being labelled as and exposed as making mistakes, resulting in playing blaming and defending games. In this regard, Dietz et al. ${ }^{37}$ argue that culture does not only determine how 'we think and what we do ...', but also determines 'what we understand as foundational to trust and what we consider as trustworthy'.

The power-duty of members of this committee is thus located outside of this committee but within the same institution. The subsequent influence of the deliberations within the committee on decisions outside the committee is experienced as a reality. This reality broadens the understanding of conflict of interest to those attributes articulated by the OECD as the improper influence of official duties and responsibilities. ${ }^{38}$ This reality is furthermore confirmed by Williams-Jones and MacDonald ${ }^{8}$ as instances of threatened objectivity, impartiality and credibility of judgements (thus not necessarily decisions), which may lead to 'a subsequent loss of trust by staff, students and the broader public'. This possible influence on decisions outside the committee is also described by Van Ees et al. ${ }^{7}$ when they specifically include interactions and processes 'outside the boardroom' and the reality of coalitions of actors and objectives resulting from political bargaining. Thus, the behaviour of individuals with a conflict of interest or a vested hidden agenda in the committee may have an influence outside this committee, as the deliberations in the committee may determine the mood for decisions taken by other bodies.

\section{Conclusion}

The question this article set out to answer was whether a conflict of interest is possible within a committee with no decision-making powers, and if so, what the nature of such conflict may be. A review of the literature showed that this question is important within the context of corporate governance in general and sound corporate governance of HEIs in particular.

A non-decision-making committee within the formal governance structures of a public university was selected as a typical case of a non-decision-making committee. The researchers subsequently embarked on an exploratory qualitative study comprising qualitative content analysis of the constituting and operational documents of this committee, as well as on a study of the perceptions and lived experiences of the members of this committee.

From the findings, it was evident that the committee was established to be a high-level consultative body assisting the executive management of the university to make informed (coordinating, integrating, monitoring, evaluating, performing and ensuring) decisions of a strategic operational nature in the interest of the HEI under study. However, at the time, this committee did not have any decision-making duties. Although members of this committee were expected to declare any possible conflict of interest when signing the attendance register, none of them had ever declared a conflict of interest.

Furthermore, it emerged from the perceptions and lived experiences of the committee members that two perspectives about the possibility of a conflict of interest within the committee existed. Both perspectives related to the agenda as metaphor. One group of committee members perceived conflict of interest from the perspective of an explicit agenda. According to them, a conflict of interest within a nondecision-making committee was not possible. The other group approached the question from the hidden agenda 
perspective. According to them, they had lived experiences of the reality of a conflict of interest.

This study contributes to the existing literature on conflict of interest with a principled definition of the concept. This definition is informed by the definitions provided by Guzzetta $^{24}$ and DeAngelis, ${ }^{36}$ who identified three defining attributes of the concept 'conflict of interest', namely, a person with a legally established position, two different locations of interest and members discharging their power-duties. The implication of these principled attributes is that it enables a comparison of the two agenda perspectives with each other (see Table 1).

The two agenda perspectives seem to agree on the first attribute, namely, the legally established position of the members of the particular committee. They differ with respect to the interpretation of the second and third attributes. With regard to the two different interest locations, the explicit agenda perspective views the conflicting interest as one of a private or personal interest outside the institution. In terms of the hidden agenda perspective, the conflicting interest does not need to be private or outside the institution, but can be a sector-specific interest within the institution. This sector-specific interest may become personal for the committee member, which may impair decisions on other platforms within the same institution. These decisions refer to the third attribute, namely, members' discharge of their power-duties. The explicit agenda perspective holds that the power-duty is discharged through decisions within the committee. As this specific committee does not have any decision-making duties, it is argued that conflict of interest is per definition not possible.

This study found that there is a need for a logical and principled definition of the concept 'conflict of interest' within the context of higher education and the public sector at large. Definitions referring specifically to conflicting interests as private and outside the institution, and also specifying the context to impairing decisions of the relevant committee, provide ethical escape routes to committee members. Applying the hidden agenda perspective, namely, that a conflict of interest refers to any conflicting interest (within and outside the institution), may impair a committee member's rights to exercise his or her power-duties inside or outside that committee.

As this study revealed the reality of sectoral conflict of interest within a single institution and institutional

TABLE 1: An agenda perspective on conflict of interest within the selected committee.

\begin{tabular}{lll}
\hline $\begin{array}{l}\text { Defining attributes of } \\
\text { 'conflict of interest' }\end{array}$ & Explicit agenda & Hidden agenda \\
\hline $\begin{array}{l}\text { Legally established } \\
\text { position }\end{array}$ & $\begin{array}{l}\text { Position determined by } \\
\text { 'Terms of Reference' }\end{array}$ & $\begin{array}{l}\text { Position determined by } \\
\text { 'Terms of Reference' }\end{array}$ \\
$\begin{array}{l}\text { Two different interest } \\
\text { locations }\end{array}$ & $\begin{array}{l}\text { Institutional versus private } \\
\text { or personal interest } \\
\text { outside the institution }\end{array}$ & $\begin{array}{l}\text { Institutional versus } \\
\text { sectoral and personal } \\
\text { (within institution) interests }\end{array}$ \\
Fulfilling power-duties & Not fulfilling power-duties & $\begin{array}{l}\text { Power-duties fulfilled } \\
\text { outside the committee }\end{array}$ \\
\hline
\end{tabular}

committee, there is a need for further research on, inter alia, strategies to mitigate this governance risk.

\section{Acknowledgements}

The authors wish to thank the University of South Africa for providing the opportunity and permission to conduct this study.

\section{Competing interests}

The authors declare that they have no financial or personal relationships that may have inappropriately influenced them in writing this article.

\section{Authors' contributions}

J.S.W. and E.S. contributed equally to the design and implementation of the research, to the analysis of the results and to the writing of the manuscript.

\section{Funding information}

This research received no specific grant from any funding agency in the public, commercial or not-for-profit sectors.

\section{Data availability}

The data for this study consist of interview transcriptions. De-anonymised copies are available from the corresponding author, J.W., on reasonable and written request.

\section{Disclaimer}

The views and opinions expressed in this article are those of the authors and do not necessarily reflect the official policy or position of any affiliated agency of the authors.

\section{References}

1. Institute of Directors of Southern Africa (IODSA). King IV Report on Corporate Governance for South Africa 2016 [homepage on the Internet]. 2016 [cited 2020 Apr 21]. Available from: www.iodsa.co.za

2. Cavico FJ, Mujtaba BG. The state of business schools, business education, and business ethics. J Acad Bus Ethics. 2009;2(1):1-7.

3. De Cremer D, Van Dick R, Tenbrunsel A, Pillutla M, Murnighan JK. Understanding ethical behavior and decision making in management: $A$ behavioural business ethics approach. Br J Manag. 2011;22:S1-S4. https://doi. org/10.1111/j.1467-8551.2010.00733.x

4. Seyam AS, Cooper BN. The New York Nonprofit Revitalization Act of 2013: Enhancing the governance and accountability of the not-for-profit organizations around the world. GSTF J Bus Rev. 2015;4(1):31-34. https://doi.org/10.7603/ s40706-015-0005-6

5. Organisation for Economic Co-operation and Development (OECD). Managing conflict of interest in the public sector: A toolkit. Organisation for Economic Co-operation and Development: Paris; 2005. https://doi.org/10.1787/ 9789543370382-bg

6. Hall M, Symes A, Luescher TM. 2002, Governance in South African higher education [homepage on the Internet]. Council of Higher Education. [cited 2020 Apr 21] Available from: http://www.che.org.za/documents/d000006/Governance_Research_ Report.pdf

7. Van Ees H, Gabrielsson J, Huse M. Toward a behavioral theory of boards and corporate governance. Corp Govern Int Rev. 2009;17(3):307-319. https://doi. org/10.1111/j.1467-8683.2009.00741.x

8. Williams-Jones B, MacDonald C. Conflict of interest policies at Canadian universities: Clarity and content. J Acad Ethics. 2008;6(1):79-90. https://doi. org/10.1007/s10805-007-9052-6

9. Bureau of Market Research (BMR). Self-assessment survey: Unisa Extended Management Committee. Pretoria: UNISA; 2015. 
10. Republic of South Africa (RSA). Higher Education Act 101 of 1997, as amended. Pretoria: Government Printer; 1997.

11. Department of Higher Education and Training (DHET). Regulations for reporting by public higher education institutions (Government Notice R464 of 9 June 2014) [homepage on the Internet]. 2014 [cited $2020 \mathrm{Apr} 21$ ]. Available from: http://jutastat.juta.co.za/nxt/gateway.dll/strg/sargstat/full_notice/4918_full notice? $f=$ templates $\$ \mathrm{fn}=$ default.htm Regulations

12. Republic of South Africa (RSA). Standard Institutional Statute, subject to Section 33 of the Higher Education Act, 1997 (Act 101 of 1997), as amended [homepage on the Internet]. 2002 [cited 2020 Apr 21]. Available from: http:// jutastat.juta.co.za/nxt/gateway.dll/strg/sargstat/full_notice/4908_full jutastat.juta.co.za/nxt/gateway.

13. Department of Education (DoE). The Statute of the University of South Africa as amended (Government Notice 108 of 03 February 2006). Pretoria: Government Printer; 2006.

14. Department of Higher Education and Training (DHET). Amendments to the institutional statute: University of South Africa (Government Notice 1077 of 19 December 2012). Pretoria: Government Printer; 2012.

15. Department of National Treasury. 2019 estimates of national expenditure: Vote 15: Higher Education and Training [homepage on the Internet]. 2019 [cited $2020 \mathrm{Apr}$ 21]. Available from: http://www.treasury.gov.za/documents/ NationalBudget/2019/ene/Vote15HigherEducationandTraining.pdf

16. University of South Africa (UNISA). 2017 annual report. UNISA: Pretoria; 2018

17. Chaghadari MF, Chaleshtori GN. Corporate governance and firm performance. 2011 International Conference on Sociality and Economics Development. Kuala Lumpur, Malaysia: IACSIT Press, 2011, June 04-05; p. 484-489.

18. Wang $\mathrm{ZH}$. Turf war or collusion: An empirical investigation of conflict of interest between large shareholders. Corp Govern Int Rev. 2017;25(5):358-380. https:// doi.org/10.1111/corg.12207

19. Parker LD. Internal governance in the nonprofit boardroom: A participant observer study. Corp Govern Int Rev. 2007;15(5):923-934. https://doi. org/10.1111/j.1467-8683.2007.00607.x

20. Geuna A, Muscio A. The governance of university knowledge transfer: A critical review of the literature. Minerva. 2009;47(1):93-114. https://doi.org/10.1007/ s11024-009-9118-2

21. Barac K, Marx B, Moloi T. Corporate governance practices at South African highe education institutions: An annual report disclosure analysis. J Econ Financ Sci. 2011;4(2):317-332. https://doi.org/10.4102/jef.v4i2.323

22. Burnaby PA, Abdolmohammadi MJ, Hass S, et al., editors. A global summary of the common body of knowledge 2006. Altamonte Springs, FL: The Institute of Internal Auditors Research Foundation; 2006

23. Arnwine DL. Effective governance: The roles and responsibilities of board members. Proc (Bayl Univ Med Cent). 2002;15(1):19-22. https://doi.org/10.1080 /08998280.2002.11927809
24. Guzzetta G. Legal standards and ethical norms defining the limits of conflicts regulations. In: Trost C, Gash AL, editors. Conflict of interest and public life: Crossnational perspective. Cambridge: Cambridge University Press, 2008; p. 95-124. national perspective. Cambridge: Cambridge
https://doi.org/10.1007/978-3-319-41830-8_5

25. PwC. Moving forward: Trends in annual reporting by South African public higher universities [homepage on the Internet]. 2014 [cited 2020 May 5]. Available from: https://www.pwc.co.za/en/assets/pdf/higher-education-conference-movingforward.pdf

26. University of South Africa (UNISA). Unisa code of ethics and conduct. UNISA: Pretoria; 2009.

27. University of South Africa (UNISA). Terms of reference: Extended management committee. UNISA: Pretoria; 2015.

28. Babbie E, Mouton J. The practice of social research. Oxford: Oxford University Press; 2001

29. Humble ÁM. Technique triangulation for validation in directed content analysis. In J Qual Methods. 2009;8(3):34-51. https://doi.org/10.1177/160940690900800305

30. Pietkiewicz I, Smith JA, Pietkiewicz I, Smith JA. A practical guide to using interpretative phenomenological analysis in qualitative research psychology. Psychol J. 2014;20(1):7-14. https://doi.org/10.14691/cppj.20.1.7

31. Oosthuizen RM, Naidoo V. Attitudes towards and experience of employment equity. SA J Ind Psychol. 2010;36(1):1-9. https://doi.org/10.4102/sajip.v36i1.836

32. Parris MA, Vickers MH. Working in teams: The influence of rhetoric - From sensemaking to sadness. Admin Theor Prax. 2005;27(2):277-300. https://doi.org /10.1080/10841806.2005.11029488

33. De Witt L, Ploeg J. Critical appraisal of rigour in interpretive phenomenological nursing research. J Adv Nurs. 2006;55(2):215-229. https://doi.org/10.1111/j.13652648.2006.03898.x

34. University of South Africa (UNISA). Institutional statute of the University of South Africa. UNISA: Pretoria; 2012.

35. Parker R, Bradley L. Organisational culture in the public sector: Evidence from six organisations. Int J Public Sect Manag. 2000;13(2):125-141. https://doi. org/10.1108/09513550010338773

36. DeAngelis W. Academic deans, codes of ethics, and ... fiduciary duties? J Acad Ethics. 2014;12(3):209-225. https://doi.org/10.1007/s10805-014-9212-4

37. Dietz G, Gillespie N, Chao GT. Unravelling the complexities of trust and culture. In Saunders MNK, Skinner D, Dietz G, Gillespie N, Lewicki RJ, editors. Organizationa trust: A cultural perspective. Cambridge: Cambridge University Press, 2010; p. 3-41.

38. Organisation for Economic Co-operation and Development (OECD). Board practices: Incentives and governing risks, corporate governance. Paris: OECD Publishing; 2011. https://doi.org/10.1787/9789264113534-en

39. Wessels JS, Visagie R. Risk assessment of social science research in Africa. In Nortjé $N$, Visagie R, Wessels JS, editors. Social science research ethics in Africa. Cham: Springer, 2019; p. 73-87. https://doi.org/10.1007/978-3-030-15402-8_6 